\title{
Rheological properties of milk-based desserts with the addition of oat gum and $\kappa$-carrageenan
}

\author{
Piotr Zarzycki $^{1}$ (1) $\cdot$ Aleksandra Elżbieta Ciołkowska ${ }^{1}$ Ewa Jabłońska-Rys ${ }^{1}$ • \\ Waldemar Gustaw ${ }^{1}$
}

Revised: 19 June 2019/Accepted: 24 July 2019/Published online: 1 August 2019

(C) The Author(s) 2019

\begin{abstract}
A growing interest in development of milk desserts with good nutritional and rheological properties can be observed. A good and stability rheological as well as nutritional properties of such desserts can be provided by applying suitably composed gum mixtures. In this work, the effect of $0.1 \% \mathrm{~K}$-carrageenan addition on the rheological properties of based-milk desserts with different oat gum concentrations $(0.1,0.3$ and $0.5 \%)$ was investigated. All milk desserts tested in presented study showed a time dependent and shear-thinning flow behavior. The mechanical spectra were characterized by storage module $\left(G^{\prime}\right)$ greater than loss module (G”), typical for viscoelastic materials such as gels and dispersions. The incorporation of $0.1 \% \kappa$-carrageenan into milk dessert with different oat gum concentrations allows to obtain stronger gel structure compared to milk dessert with separate oat gum addition. It can be also observed that desserts systems with the $0.1 \% \mathrm{~K}$ carrageenan had more stable viscoelastic properties. Moreover, the use the $\kappa$-carrageenan addition caused an increase in consistency coefficient $(\mathrm{K})$ and decreased in $\mathrm{n}$-value for Ostwald de Waele rheological model. Combined addition of oat gum and carrageenan allows to obtain milk dessert with stronger texture. The hardness of milk desserts range from 0.32 to $0.49 \mathrm{~N}$ for desserts without $\kappa$ carrageenan addition and from 0.513 to $0.557 \mathrm{~N}$ for desserts with $\kappa$-carrageenan. The high synergistic effect of composed gum mixtures on rheological properties of milk
\end{abstract}

Piotr Zarzycki

piotr.zarzycki@up.lublin.pl

1 Department of Plant Food Technology and Gastronomy, University of Life Sciences in Lublin, ul. Skromna 8, 20-704 Lublin, Poland dessert occurs at $0.1 \%$ oat gum and $0.1 \%$ k-carrageenan concentration.

Keywords Dairy dessert - Flow behaviour - Mechanical spectra $\cdot$ Texture

\section{Introduction}

Milk-based desserts due to their sensory and nutritional characteristics are widely consumed by different groups of consumers, such as children, adults and elderly people (Nastaj et al. 2007; Toker et al. 2013; Szwajgier and Gustaw 2015; Aguilar-Raymundo and Vélez-Ruiz 2018). Basically, milk-based desserts are formulated with whole and/or skimmed milk, different kind of thickeners such as starch and hydrocolloids, sucrose, colorants and aroma. The rheological and textural properties of these products are very important in terms of industrial manufacturing, preparation in the kitchen, consumer acceptance, and nutritive characteristics (Reis et al. 2011; Toker et al. 2013). In general, this type of product shows time dependent and shear-thinning flow behavior, and viscoelastic properties typical for weak gels. However, noticeable differences in rheological properties can be found in model systems with different compositions (Tárrega and Costell 2006; Szwajgier and Gustaw 2015; Aguilar-Raymundo and Vélez-Ruiz 2018). When new components or its combinations are incorporated into products, the effect of such modification on rheological and textural properties should be researched.

One of the typical hydrocolloid used as a thickener in dairy/milk desserts is carrageenan. Carrageenan consists of a linear sulphated polysaccharide, namely O- $\beta$-D-galactopyranosyl-4-sulfate-(1-4)-O-3,6-anhydro- $\alpha$-D- 
galactopyranosyl-(1-3), obtained from red seaweeds. The most commonly used carrageenan fractions include $\kappa-$, $1-$ and $\lambda$-carrageenan (Gustaw 2008a). $\kappa$-carrageenan forms strong and brittle gels, 1 -carrageenan gives delicate and elastic gels, whereas $\lambda$-carrageenan forms liquid and viscous solutions (Gustaw and Mleko 1998). Several studies have been focused on analyzing $\kappa$-carrageenan to improve the rheological properties of dairy desserts. According to Reis et al. (2011) $\kappa$-carrageenan due to its complex with $\kappa$ casein micelles of milk can generating a thickening effect up to 10 times higher than its effect in water. Toker et al. (2013) evaluated the effect of xanthan, guar gums, carrageenan, alginate, as well as their mixtures, on rheological properties of a dairy dessert, and found that $\kappa$-carrageenan is one of the most effective hydrocolloid influencing on rheological parameters of the dairy dessert.

In recent years, nutritional trend for foods enrichment has become very important. One of the methods of improving nutritional properties is dietary fibre supplementation, which is used practically in all food product categories. Dietary fiber, such as $(1 \rightarrow 3),(1 \rightarrow 4)$-D- $\beta$ glucan ( $\beta$-glucans), is well known to confer significant health-promoting properties. $\beta$-glucans, mostly found in oat and barley, exhibit many health benefits including the reduction of colon cancer risk, reduction of total and lowdensity lipoprotein content and the regulation of postprandial blood glucose and insulin levels (Sayar et al. 2006; Weickert et al. 2006; Keith et al. 2014; Patel 2015). The ability of $\beta$-glucans to impart gut viscosity is one of the main hypothesis, apart from colonic fermentation, explaining the health-promoting effect of $\beta$-glucans (Anttila et al. 2004; Queenan et al. 2007). The increased gut viscosity is believed to be one of the key mechanism responsible for lower absorption of sugars and bile acid. The role of viscosity of $\beta$-glucans in reducing the postprandial glucose and insulin rise, as well as lowering of plasma cholesterol is well documented in literature (Wood et al. 1994; Reppas et al. 2009; Wolever et al. 2010). Apart from its nutritional benefits, $\beta$-glucans has been often proposed to use in food formulation due to their rheological characteristics; i.e., gelling properties and viscosity enhancement (Gustaw 2008b; Gustaw and Szwajgier 2012; Lazaridou et al. 2014).

The use of two or more gums in the product formulation is wildly widespread in the food industry due to the synergistic effect of gum mixture. The proper gum combination may improve product quality including nutritional properties, and also provide economic benefits (Toker et al. 2013; Qasem et al. 2017). Previous studies on mixtures of milk proteins with oat gum, showed a segregative phase separation, which resulted in a significant deterioration of rheological properties of products containing higher concentrations of oat gum (Gustaw 2008b; Gustaw and
Szwajgier 2012). To best of our knowledge, there are many studies about the specific and synergic effect of gums in different food product categories, also in dairy desserts (Reis et al. 2011; Toker et al. 2013; Lazaridou et al. 2014), but there is a lack of information in literature about the effects of combination use oat gum and $\kappa$-carrageenan in milk desserts on rheological and textural product properties.

Thus, based on the aforementioned studies, the aim of this study was to investigate the effect of oat gum concentrations on the rheological properties of milk-based dessert model systems containing $\kappa$-carrageenan.

\section{Materials and methods}

\section{Materials}

The following materials were used in the study oat gum obtained from high fibre oat bran with $(1 \rightarrow 3)$, $(1 \rightarrow 4)$ D- $\beta$-glucans contents of $7.50 \pm 0.6 \%$ (PZZ Kruszwica, Poland), skim milk powder (SMP) containing 34\% of protein (SM Gostyń, Poland), א-carrageenan (Sigma, USA), modified tapioca starch T-440 (E-1422, Avebe, Veendam, Holand) and sucrose.

\section{Extraction of oat gum from oat bran (GO)}

The oat gum was isolated from the oat bran using method of Beer et al. (1996). $6 \mathrm{~g}$ of oat bran was blended with $90 \mathrm{ml}$ of distilled water at $40{ }^{\circ} \mathrm{C}$, and mixed for $15 \mathrm{~min}$ (magnetic stirrer type MS $11 \mathrm{HS}$, Wigo, Poland, $500 \mathrm{rpm}$ ). Then, the $\mathrm{pH}$ of mixture was adjusted to 10 with $20 \%$ sodium carbonate and stirred for addition $30 \mathrm{~min}\left(40{ }^{\circ} \mathrm{C}\right.$, $500 \mathrm{rpm}$ ). The mixture was centrifuged (Sigma 4K15, Polygen, Poland, $2000 \times g, 10 \mathrm{~min}$ ), and the supernatant was decanted (E1). The residue was reextracted at the condition described above and extract (E2) was obtained. The mixture of two extracts (E1 and E2) were cooled to $20{ }^{\circ} \mathrm{C}, \mathrm{pH}$ was adjusted to 4.5 with $20 \%$ (v/v) hydrochloric acid and then centrifuged $(2000 \times g, 10 \mathrm{~min})$. The supernatant gum extract was cooled to $10{ }^{\circ} \mathrm{C}$, mixed with absolute ethanol $(1: 1 \mathrm{v} / \mathrm{v})$ and centrifuged $(2000 \times g$, $10 \mathrm{~min}$ ). The gum solids were collected, dried (freeze dryer type Alpha 1-2 LD plus, Christ, Germany) and ground (GM 200 , Retsch $\mathrm{GmbH}$, Germany) to pass a $250 \mu \mathrm{m}$ screen. The obtained oat gum isolate contained $82.0 \pm 0.3 \%$ of $\beta$ glucan. The content of $(1 \rightarrow 3),(1 \rightarrow 4)$-D- $\beta$-glucan was determined with the McCleary method (AACC Method 32-23), using Megazyme enzymes and methodological procedures (Megazyme International, Wicklow, Ireland). 


\section{Composition and preparation of the milk dessert}

The base formulation for the milk dessert consisted of $11.75 \%$ of skim milk powder, $3 \%$ of modified tapioca starch and $8 \%$ of sucrose. This formula was enriched by addition of oat gum $(0,0.1,0.3,0.5 \%)$ and $\kappa$-carrageenan ( 0 or $0.1 \%)$. Table 1 shows the compositions and identification codes for all the formulations. The following procedure was used for the milk dessert preparation. First, all ingredients (skim milk powder, tapioca starch, sucrose oat gum and $\kappa$-carrageenan) were weighted, according to formula, and dispersed slowly in the correspondent $0.1 \mathrm{~mol} / \mathrm{L}$ $\mathrm{NaCl}$ solution to obtain $30 \mathrm{~mL}$, for 30 min under constant stirring at $70{ }^{\circ} \mathrm{C}$ (magnetic stirrer MS $11 \mathrm{HS}$, Wigo, Poland). Subsequently, the mixture was heated up to $95{ }^{\circ} \mathrm{C}$, kept for $15 \mathrm{~min}$ on a heating laboratory bath (W-215, Laboplay, Poland) and then each formulation was allowed at cool down until room temperature. After that, the milk desserts were transferred into beakers and storage $(24 \mathrm{~h}$, $4{ }^{\circ} \mathrm{C}$ ) prior to texture measurements.

\section{Viscoelastic behavior of milk dessert}

Rheological evaluations were completed using a dynamic rheometer RS 300 (ThermoHaake, Karlsruhe, Germany) monitored by Haake RheoWin 3.61, using a concentric cylinder geometry (Z41). The frequency sweep was conducted at samples temperature $20{ }^{\circ} \mathrm{C}$, regulated by DC 30 circulator (ThermoHaake, Karlsruhe, Germany), with oscillation frequencies ranging from 0.1 to $100 \mathrm{~Hz}$, in which the values of the storage modulus ( $\left.\mathrm{G}^{\prime}\right)$ and the loss modulus (G") were recorded as a function of frequency. Three replicates were completed for each sample.

\section{Flow behavior of milk dessert}

The flow curves of milk desserts were measured by recording shear stress values when shearing the samples with a linear increasing shear rate from 1 to $200 \mathrm{~s}^{-1}$ for a period of $60 \mathrm{~s}$. Data were fitted to the Ostwald de Waele (Eq. 1) and Herschel-Bulkley (Eq. 2) models, where $\sigma$ (Pa) is shear stress, $\mathrm{K}\left(\mathrm{Pa} \mathrm{s}^{\mathrm{n}}\right)$ is consistency coefficient, $\gamma$ $\left(\mathrm{s}^{-1}\right)$ is the shear rate, $\sigma_{\mathrm{o}}(\mathrm{Pa})$ is yield stress, and $\mathrm{n}$ which is flow index is dimensionless, using Haake RheoWin software, version 3.61 (ThermoHaake, Germany).

$$
\begin{aligned}
& \sigma=\mathrm{K} \gamma^{\mathrm{n}} \\
& \sigma=\sigma_{o}+\mathrm{K} \gamma^{\mathrm{n}}
\end{aligned}
$$

Time depending behavior of milk dessert was evaluated by recording up and down shear stress values between shear rates of $1-200 \mathrm{~s}^{-1}$ for a period of $60 \mathrm{~s}$, and in a reverse sequence for the same time. The thixotropic area $\left(\mathrm{A}_{\mathrm{T}}\right)$ showing the difference between areas under the upstream data point curve and under the downstream data point curve were obtained using Haake RheoWin software, version 3.61 .

\section{Texture analysis of milk dessert}

The texture profile analyses test (TPA) were performed, in six repeats, by a penetration test using stainless steel cylindrical probe ( $15 \mathrm{~mm}$ diameter) at the crosshead speed of $1 \mathrm{~mm} / \mathrm{s}$ and $70 \%$ deformation. The TA-XT2i Texture Analyser (Stable Microsystems, Goaldming, UK) with software Texture Export ver. 1.22 was used in the study. Five parameters were measured during TPA: hardness $(\mathrm{N})$, springiness (m), cohesiveness (no unit), gumminess $(\mathrm{N})$ and chewiness $(\mathrm{J})$.

\begin{tabular}{|c|c|c|c|c|c|c|}
\hline \multirow[t]{2}{*}{ Code } & \multicolumn{6}{|c|}{ Composition of milk dessert (\%) } \\
\hline & SMP & Modified tapioca starch & $\kappa$-carrageenan & Saccharose & Oat gum & $0.1 \mathrm{~mol} / \mathrm{L} \mathrm{NaCl}$-solution \\
\hline 1-Con & 11.75 & 3 & 0 & 8 & 0 & 77.25 \\
\hline 2-OG0K & 11.75 & 3 & 0.1 & 8 & 0 & 77.15 \\
\hline 3-OG01 & 11.75 & 3 & 0 & 8 & 0.1 & 77.15 \\
\hline 4-OG01K & 11.75 & 3 & 0.1 & 8 & 0.1 & 77.05 \\
\hline 5-OG03 & 11.75 & 3 & 0 & 8 & 0.3 & 76.95 \\
\hline 6-OG03K & 11.75 & 3 & 0.1 & 8 & 0.3 & 76.85 \\
\hline 7-OG05 & 11.75 & 3 & 0 & 8 & 0.5 & 76.75 \\
\hline 8 -OG05K & 11.75 & 3 & 0.1 & 8 & 0.5 & 76.65 \\
\hline
\end{tabular}

Table 1 Composition and identification codes for milk dessert formulation

SMP—Skim milk powder, samples description; Con—control (0\%-oat gum, 0\%-к-carrageenan); OG0(K), OG01(K), OG03 (K), OG05(K)— samples with different oat gum concentration, respectively $0,0.1,0.3$ and $0.5 \%, \mathrm{~K}-0.1 \% \mathrm{~K}$-carrageenan addition 


\section{Statistical analysis}

Eight milk desserts systems were prepared, following a factorial design: $2 \times 4$; with two concentration levels of $\kappa$ carrageenan $(0$ and $0.1 \%)$ and four concentration levels of oat gum $(0,0.1,0.3$, and $0.5 \%)$ The levels of the factors were chosen according to the preliminary research on milk desserts. Three replicates were completed for each system (individual experimental units). The analyses were carried out $24 \mathrm{~h}$ after milk desserts preparation. Statistical analysis was performed using STATISTICA 13.0 (Stat-Soft, Cracow, Poland). Duncan test $(p \leq 0.05)$ was used to identify statistically significance of differences between mean values.

\section{Results and discussion}

\section{Viscoelastic behavior response}

Mechanical spectra obtained for milk desserts with different concentrations of oat gum and $\kappa$-carrageenan are shown in Fig. 1a-d, with both storage (G') and loss modulus (G”). The mechanical spectra, for all samples, were characterized by G' values greater than G" values, that behavior is typical for viscoelastic materials such as gels and dispersions
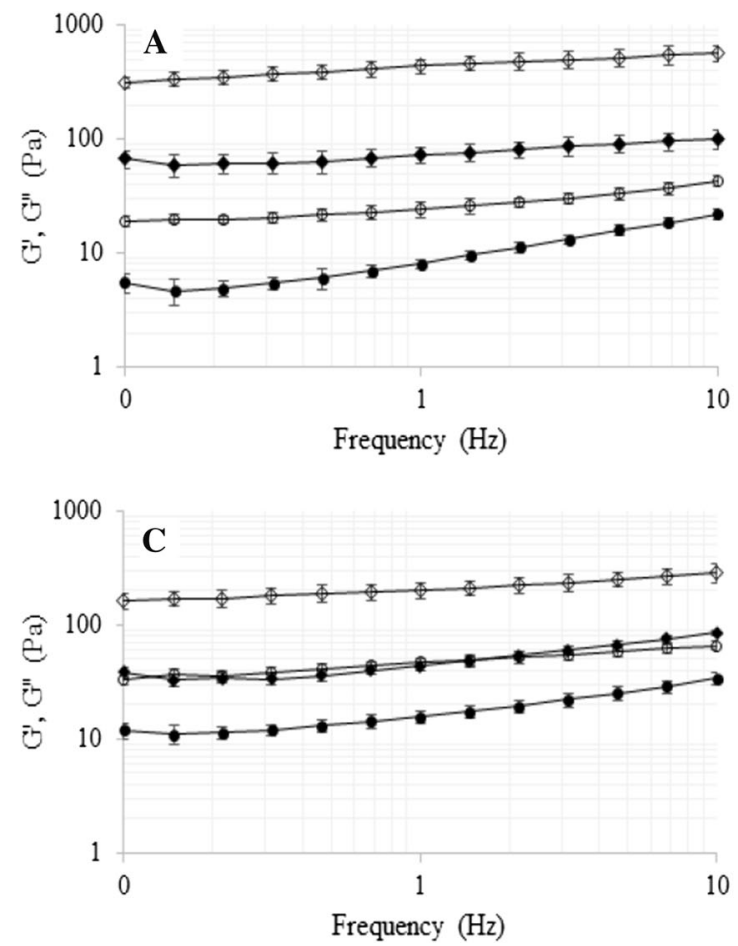

Fig. 1 Mechanical spectra for milk dessert with $0 \%$ ("open circle", "filled circle") and $0.1 \%$ ("open diamond", "filled diamond") addition of $\kappa$-carrageenan: a milk dessert without oat gum, b milk dessert with $0.1 \%$ oat gum concentration, $\mathbf{c}$ milk dessert with $0.3 \%$ oat
(Szwajgier and Gustaw 2015; Aguilar-Raymundo and Vélez-Ruiz 2018). The weak dependence on frequency of both modulus (G' and G'), characteristic for weak-gel systems, was also observed. Moreover, the addition of $\kappa$ carrageenan to the milk desserts decreased the frequency dependence of loss modulus (G"). The slight increase of both modulus observed in this study, can be attributed to the absence of binding agents (gluten, starch) in the dairy dessert samples (Sivaramakrishnan et al. 2004). In none of the tested samples a decrease in the $G^{\prime}$ value with increasing frequency was observed, which could indicating the destruction of the gel matrix.

As expected, the G' and G" values were higher for milkdessert with oat gum addition compared to control (Fig. 1a-d), however, there was no linear relationship between the concentration of oat gum and both modulus value ( $G$ ' and $G$ "). Among the desserts without $\kappa$-carrageenan addition, the highest $G$ ' and $G$ " values were observed for $0.1 \%$ oat gum concentration (Fig. 1b). The G' and G" values for dessert with 0.3 and $0.5 \%$ oat gum concentration (Fig. 1c and d, respectively) were much lower compared to values noted for $0.1 \%$ oat gum concentration, but still higher compared to control (Fig. 1a-d).

This behavior can be explained by the occurrence of segregative phase separation between probably between casein and oat gum (Gustaw 2008b; Gustaw and Szwajgier
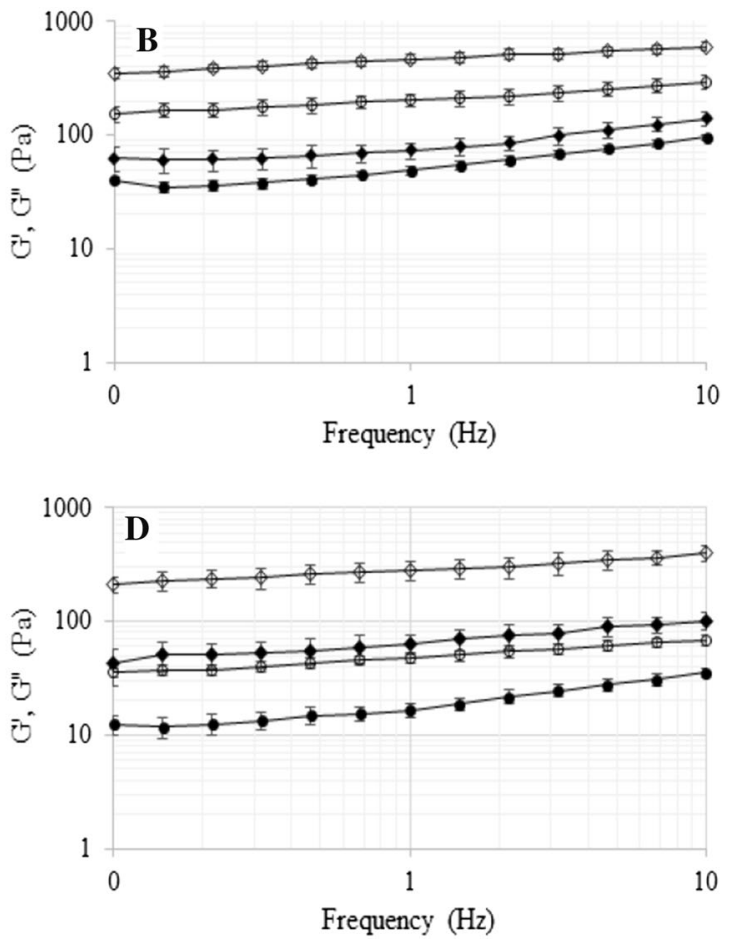

gum concentration, $\mathbf{d}$ milk dessert with $0.5 \%$ oat gum concentration. Empty symbols for the storage modulus (G') and filled symbols for the loss modulus (G") 
2012). Aqueous biopolymer mixtures are in most cases characterized by a thermodynamic incompatibility that leads to a macroscopic phase separation (Mekhloufi et al. 2005). According to Bergfeldt et al. (1996) the phase separation of two biopolymers in a common solvent may be divided into two main categories: associative and segregative phase separation. In an associative phase separation, both biopolymers are enriched in one of the separating phases with the other phase containing mostly solvent. This type of phase separation is often obtained for oppositely charged biopolymer mixtures. In a segregative phase separation, two polymers are separated into two different phases. This is the case mainly for two nonionic biopolymers, two similarly charged polyelectrolytes, or a polyelectrolyte plus a nonionic biopolymer.

It may be observed that the addition of $0.1 \% \mathrm{\kappa}$-carrageenan results in higher strengthening of the gel structure (higher G' and G" values observed), compared to $0.1 \%$ addition of oat gum (Fig. 1a and b). These data are in agreement with previous studies presented by Toker et al. (2013) in which dairy desserts containing carrageenan had the highest G', G", and lowest $\tan \delta$ (G'/G') values among dessert with different kind of gum addition (carrageenan, alginate, guar and xanthan gums and their combinations). Moreover as showed in presented study, the addition of $0.1 \% \mathrm{~K}$-carrageenan to milk dessert with different oat gum concentrations allows to obtain stronger gel structure compared to milk dessert with separate oat gum addition (higher G' and G" values observed). However, similar pattern to dessert samples with separate oat gum concentration was observed, that means the highest G' and G" values were obtained for milk dessert with $0.1 \%$ oat gum concentration (Fig. 1b). An increase in oat gum concentration to 0.3 and $0.5 \%$ (Fig. $1 \mathrm{c}$ and $\mathrm{d}$, respectively) resulted in decrease G' and G" values, but the noted values for both moduli were higher compared to dessert with separate oat gum addition, regardless of the amount of oat gum concentration. Probably carrageenan reduced the negative effect of the separation phase between milk proteins and oat gum on the rheological properties of the tested dairy desserts, but $0.1 \%$ carrageenan concentration did not completely eliminate the effect of this phenomenon on the deterioration of rheological properties analyzed samples.

The results obtained in this study indicate that, the addition of oat gum has a greater impact on viscous than elastic properties of milk-based desserts compared to $\kappa$ carrageenan addition. Increasing the concentration of oat gum above $0.1 \%$ leads to a weakening of the gel structure. The use of $\kappa$-carrageenan gives, the possibility of using higher concentration of oat gum in milk dessert, up to $0.5 \%$.

\section{Flow behavior response}

All milk desserts, obtained in this study, exhibited time dependent (thixotropic or antithixotropic) and shear-thinning flow behavior. Flow curves and viscosity curves for milk dessert are shown in Fig. 2, correspond to milk dessert with $0 \%$ (A) and $0.1 \%$ (B) addition of $\kappa$-carrageenan respectively. The flow curves showed a similar pattern although clear differences were observed among them, depending on oat gum concentration and $\kappa$-carrageenan additions. The flow curves of eight analyzed milk dessert showed a non-Newtonian response, exhibiting a yield stress and a shear thinning flow-increase in shear stress (decrease in apparent viscosity) with increase in shear rate. That behavior is usually observed in weak gel systems, witch in accordance with previously described results, shown in Fig. 1a-d. Similar flow behavior have been reported by other researchers for milk-based desserts with addition of $\kappa$-carrageenan, starch, brewery malts and chickpea flour (Mleko and Gustaw 2002; Szwajgier and Gustaw 2015; Aguilar-Raymundo and Vélez-Ruiz 2018).

The addition of oat gum allows to obtained milk dessert with higher value of shear stress compared to control (samples 3, 5, 7 vs 1), but it should be noticed that the highest shear stress values were observed for milk dessert with $0.1 \%$ oat gum concentration. With increase oat gum concentration above $0.1 \%$ the shear stress decreases. That pattern occurs for both tested type of milk desserts-with or without $\kappa$-carrageenan addition (Fig. $2 a$ and $b$, respectively). Additionally, the highest shear stress values for milk desserts prepared with the addition of $\kappa$-carrageenan were observed (Fig. 1a and b), when the samples with the corresponding oat gum concentration are compared. The shear stress value for milk desserts without $\kappa$-carrageenan, at the highest shear rate applied $200 \mathrm{~s}^{-1}$, were $226.2 \mathrm{~Pa}$, 174.9 $\mathrm{Pa}, 172.6 \mathrm{~Pa}$ and $49.4 \mathrm{~Pa}$, respectively for $0.1 \%$, $0.3 \%, 0.5 \%$ oat gum concentration and sample control (sample 3,5,7 and 1). The corresponding values for milk dessert with $0.1 \%$ к-carrageenan addition were $289 \mathrm{~Pa}$, 244.8 Pa, 218.4 Pa and 226.6 Pa respectively for $0.1 \%$, $0.3 \%, 0.5 \%$ oat gum concentration and control (sample 4 , 6,8 and 2).

The parameters of two examined rheological models Ostwald de Waele and Herschel-Bulkley are collected in Table 2. Herschel-Bulkley model presented the best fit, characterized by highest value of $\mathrm{R}^{2}(0.933-0.998)$. It can be seen from both models that all milk desserts exhibited pseudoplastic behavior with flow index less than unity (0.301-0.453 and 0.235-0.58, respectively for HerschelBulkley and Ostwald de Waele models). Those n-values obtained in this study are in agreement with values obtained by other research for milk-based desserts with inulin and chickpea flour (Tárrega and Costell 2006; 

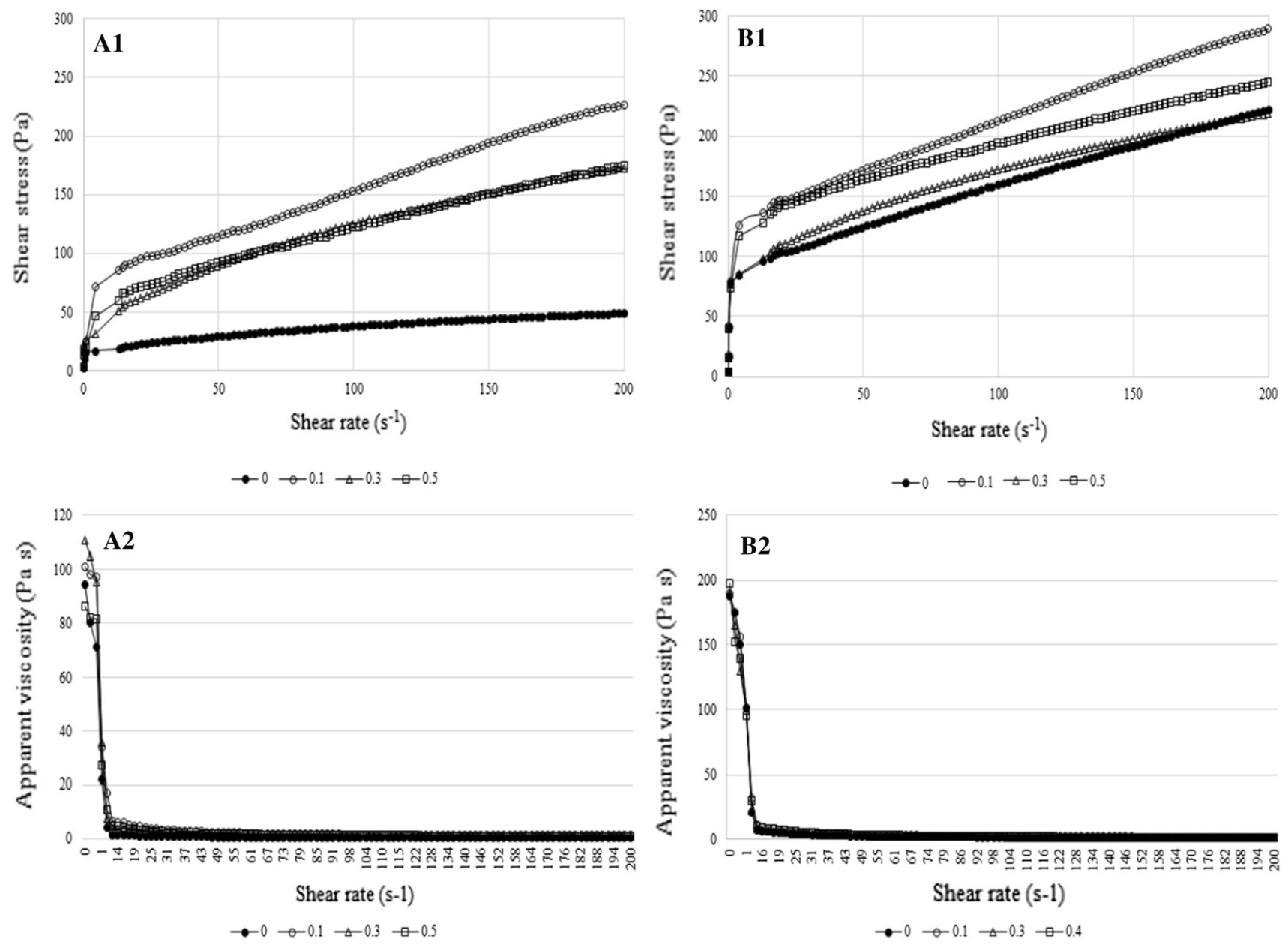

Fig. 2 Flows curves (A1, B1) and viscosity curves (A2, B2) of milk desserts with different content of oat gum $(0,0.1,0.3$, and 0.5$)$ : a and b correspond to milk dessert with 0 and $0.1 \%$ addition of $\kappa$-carrageenan respectively

Table 2 Rheological parameters (Ostwald de Waele and Herschel-Bulkley models) and thixotropic area for milk dessert systems

\begin{tabular}{|c|c|c|c|c|c|c|c|c|}
\hline \multirow[t]{2}{*}{ Code } & \multicolumn{3}{|c|}{ Ostwald de Waele model } & \multicolumn{4}{|c|}{ Herschel-Bulkley model } & \multirow[t]{2}{*}{$\mathrm{A}_{\mathrm{T}}(\mathrm{Pa} / \mathrm{s}$} \\
\hline & $\mathrm{N}$ & $\mathrm{K}\left(\mathrm{Pa} \mathrm{s}^{\mathrm{n}}\right)$ & $\mathrm{R}^{2}$ & $\mathrm{~N}$ & $\mathrm{~K}\left(\mathrm{~Pa} \mathrm{~s}^{\mathrm{n}}\right)$ & $\sigma_{\mathrm{o}}(\mathrm{Pa})$ & $\mathrm{R}^{2}$ & \\
\hline \multicolumn{9}{|c|}{ Milk desserts without $\kappa$-carrageenan } \\
\hline 1-Con & 0.580 & 7.026 & 0.906 & 0.330 & 8.439 & 16.21 & 0.985 & $5677^{\mathrm{b}}$ \\
\hline 3-OG01 & 0.302 & 33.395 & 0.958 & 0.368 & 29.560 & 25.09 & 0.933 & $9495^{\mathrm{a}}$ \\
\hline 5-OG03 & 0.455 & 13.090 & 0.960 & 0.453 & 15.567 & 26.72 & 0.998 & $-2785^{d}$ \\
\hline 7-OG05 & 0.464 & 15.669 & 0.970 & 0.383 & 21.36 & 20.09 & 0.976 & $-2824^{\mathrm{c}}$ \\
\hline \multicolumn{9}{|c|}{ Milk desserts with $0.1 \%$-carrageenan } \\
\hline 2-OG0K & 0.509 & 11.595 & 0.899 & 0.336 & 35.148 & 78.63 & 0.965 & $3009^{b}$ \\
\hline 4-G01K & 0.235 & 67.885 & 0.903 & 0.301 & 55.152 & 125.90 & 0.955 & $3113^{\mathrm{b}}$ \\
\hline 6-G03K & 0.343 & 31.955 & 0.901 & 0.306 & 42.442 & 85.05 & 0.993 & $3140^{\mathrm{b}}$ \\
\hline 8-G05K & 0.421 & 29.925 & 0.881 & 0.421 & 65.232 & 117.20 & 0.973 & $3605^{\mathrm{a}}$ \\
\hline
\end{tabular}

Means in the same column (separate for milk dessert with and without $\kappa$-carrageenan) with the same letters aren't significantly different (Duncan; $p \leq 0.05), \mathrm{K}\left(\mathrm{Pa} \mathrm{s}^{\mathrm{n}}\right)$ - consistency coefficient, $\mathrm{n}$ - flow index is dimensionless, $\sigma_{\mathrm{o}}(\mathrm{Pa})$ - yield stress, $\mathrm{A}_{\mathrm{T}}$-thixotropic area $(\mathrm{Pa} / \mathrm{s})$, samples description—as Table 1
Aguilar-Raymundo and Vélez-Ruiz 2018). Meanwhile, Toker et al. (2013) reported slight lower n-value for milk desserts with different kind of gum. According to
Herschel-Bulkley model the milk desserts containing $0.1 \%$ $\kappa$-carrageenan had the higher structural resistance to flow (higher $\sigma_{0}$ value observed). The higher $\sigma_{0}$ value for 
samples containing $1 \% \mathrm{~K}$-carrageenan is indicative of the fact that the forces of the inter-particle link were greater in these samples. Moreover, the $\kappa$-carrageenan addition generally caused an increase in $K$ and decreased in $n$ value, when milk desserts with corresponding oat gum concentration are compared. The lower n-values indicating "a more" non-Newtonian nature.

According to some research Ostwald-de Waele model can also be fitted well to data obtained for milk desserts with different kind of gums used (Toker et al. 2013; Tárrega and Costell 2006). The $\mathrm{K}$ values for this model ranged from 7.026 to $33.395 \mathrm{~Pa} \mathrm{~s}^{\mathrm{n}}$ for milk desserts without $\kappa$-carrageenan and from 11.595 to $67.835 \mathrm{~Pa} \mathrm{~s}$ for milk desserts with $\kappa$-carrageenan addition. Toker et al. (2013) reported K value in the range from 7.10 to $28.42 \mathrm{~Pa} \mathrm{~s}^{\mathrm{n}}$ for milk desserts containing carrageenan, alginate, guar and xanthan gums and their combinations. According to these authors carrageenan had the highest effect on $\eta_{50}$ (apparent viscosity at shear rate $50 \mathrm{~s}^{-1}$ ), and $\mathrm{K}$ value, which is likely to have been resulted from the strong electrostatic interaction between the positively charged region of the milk protein and the negatively charged sulphate groups of carrageenan.

Considering the relative thixotropic area values $\left(\mathrm{A}_{\mathrm{T}}\right)$, it can be observed that $A_{T}$ value strongly depend on oat gum concentration especially for milk desserts without $\kappa$-carrageenan. However, the effect of oat gum concentration on $\mathrm{A}_{\mathrm{T}}$ was no linear. A low concentration of oat gum $(0.1 \%$, sample 3) caused an increase in the hysteresis loop area, and the sample showed higher $\mathrm{A}_{\mathrm{T}}$ value than control (sample 1). At a higher oat gum concentration $(0.3 \%$ and $0.5 \%$; sample 5 and 7 , respectively) low loop area can be observed. Similar pattern for milk desserts with $0.1 \% \mathrm{\kappa}$ carrageenan addition was observed. Analyzing differences among desserts samples with the same oat gum concentration, we found that the use of $\kappa$-carrageenan stabilizes the effect of oat gum concentration on $A_{T}$ value. Moreover, in this case increase in oat gum concentration increase thixotropic area value (Table 2). Assuming that a thixotropic area value can be used as an index of the energy needed to destroy the structure responsible for flow time dependence, the experimental data indicated that combined addition of oat gum and $\kappa$-carrageenan allows to increase the energy needed to breakdown such structure especially at higher oat gum concentration.

\section{The texture profile analyses (TPA)}

TPA analysis has been widely used for rapid evaluation of food texture, however, it should be mentioned that parameters evaluated in TPA are not only material constant but also depend on measurement conditions such as compression speed, temperature and strain (Nishinari et al. 2013). The most important TPA parameter evaluated in the milk desserts is hardness (Szwajgier and Gustaw 2015; Aguilar-Raymundo and Vélez-Ruiz 2018). The textural properties of the milk desserts evaluated in present study changed notably as a function of oat gum and $\kappa$-carrageenan addition (Table 3 ).

The hardness of milk desserts obtained in this study range from 0.32 to $0.49 \mathrm{~N}$ for desserts without $0.1 \% \mathrm{\kappa}$ carrageenan addition and from 0.513 to $0.557 \mathrm{~N}$ for desserts with $\kappa$-carrageenan, which indicate stronger effect of $\kappa$-carrageenan on hardness. Combined addition of oat gum and $\kappa$-carrageenan allows to obtain milk dessert with stronger texture. However, in both type of tested desserts the highest hardness for desserts with $0.1 \%$ oat gum concentration was noted, increased in oat gum concentration above $0.1 \%$ decrease hardness. A similar pattern of behavior for gumminess and chewiness was also observed. A high correlation between hardness and gumminess and chewiness for milk dessert was obtained for both type milk desserts tested in the study, which indicates the possibility of limiting the number of parameters tested in TPA (Table 4). The highest hardness, gumminess and chewiness of milk dessert for combined addition of $0.1 \%$ oat gum and $0.1 \% \kappa$-carrageenan were noted, respectively $0.557 \mathrm{~N}$, $30.23 \mathrm{~N}$ and $28.38 \mathrm{~J}$. This results indicate high synergistic effect of those two gum at that concentration. Cohesiveness was higher in milk dessert with separate oat gum addition compared to milk dessert with combined addition of oat gum and $\kappa$-carrageenan, when desserts with the same oat gum concentration are compared. This result confirm the higher effect of oat gum on viscosity properties compared to $\kappa$-carrageenan. As regards springiness, in general, there were no significant differences in springiness, between samples (Duncan test, $p \leq 0.05$ ).

According to Gustaw et al. (2005) carrageenan affects the increase in hardness of milk desserts but at high concentration $(0.3 \%)$ may cause adverse changes in milk dessert consistency. The higher hardness of milk desserts obtained with the participation of carrageenan may be the result of the interaction between milk proteins and carrageenan (Mleko and Gustaw 2002). Mleko et al. (1997) suggested that the interaction between these two hydrocolloids took place during heating at temperatures above $60{ }^{\circ} \mathrm{C}$. Other researchers suggest that the improvement of rheological properties of gels with the addition of carrageenan was caused by the separation phase between carrageenan and the proteins (Tárrega et al. 2004; Turgeon and Beaulieu 2001). The hardness of milk dessert noted in presented study was slight higher than that reported by Szwajgier and Gustaw (2015) for dairy dessert with malt, whole and skim milk, who reported a range from 0.18 to 0.33 N. Also Aguilar-Raymundo and Vélez-Ruiz (2018) reported slightly lower hardness for dairy desserts with chickpea flour $(0.133-0.391 \mathrm{~N})$. 
Table 3 The texture profile analyses test (TPA) of milk dessert

\begin{tabular}{|c|c|c|c|c|c|}
\hline Code & Hardness (N) & Springiness $(\mathrm{m})$ & Cohesiveness (no unit) & Gumminess $(\mathrm{N})$ & Chewiness (J) \\
\hline \multicolumn{6}{|c|}{ Milk desserts without $\kappa$-carrageenan } \\
\hline 1-Con & $0.320^{\mathrm{f}} \pm 0.008$ & $0.942^{\mathrm{b}} \pm 0.007$ & $0.491^{\mathrm{d}} \pm 0.013$ & $20.1^{\mathrm{d}} \pm 0.1$ & $16.7^{\mathrm{e}} \pm 0.4$ \\
\hline 3-OG01 & $0.490^{\mathrm{c}} \pm 0.011$ & $0.938^{\mathrm{b}} \pm 0.001$ & $0.589^{\mathrm{b}} \pm 0.01$ & $25.4^{\mathrm{b}} \pm 1.2$ & $24.2^{\mathrm{b}} \pm 0.1$ \\
\hline 5-OG03 & $0.417^{\mathrm{d}} \pm 0.006$ & $0.943^{\mathrm{b}} \pm 0.003$ & $0.647^{\mathrm{a}} \pm 0.004$ & $24.06^{\mathrm{b}} \pm 1.3$ & $23.5^{\mathrm{c}} \pm 0.3$ \\
\hline 7-OG05 & $0.400^{\mathrm{e}} \pm 0.01$ & $0.953^{\mathrm{a}} \pm 0.003$ & $0.643^{\mathrm{a}} \pm 0.003$ & $22.3^{\mathrm{cd}} \pm 0.8$ & $22.3^{\mathrm{c}} \pm 1.4$ \\
\hline \multicolumn{6}{|c|}{ Milk desserts with $0.1 \%$ K-carrageenan } \\
\hline 2-OG0K & $0.523^{\mathrm{b}} \pm 0.014$ & $0.937^{b} \pm 0.003$ & $0.529^{c} \pm 0.004$ & $21.5^{\mathrm{cd}} \pm 0.38$ & $20.1^{\mathrm{d}} \pm 0.7$ \\
\hline 4-OG01K & $0.557^{\mathrm{a}} \pm 0.02$ & $0.937^{\mathrm{b}} \pm 0.011$ & $0.531^{\mathrm{c}} \pm 0.003$ & $30.23^{\mathrm{a}} \pm 2.3$ & $28.38^{\mathrm{a}} \pm 2.07$ \\
\hline 6-OG03K & $0.526^{\mathrm{b}} \pm 0.05$ & $0.931^{\mathrm{b}} \pm 0.011$ & $0.538^{\mathrm{b}} \pm 0.003$ & $22.13^{\mathrm{cd}} \pm 1.24$ & $20.85^{\mathrm{cd}} \pm 1.46$ \\
\hline 8-OG05K & $0.513^{b c} \pm 0.012$ & $0.938^{\mathrm{b}} \pm 0.001$ & $0.525^{\mathrm{c}} \pm 0.001$ & $20.67^{\mathrm{cd}} \pm 1.24$ & $20.58^{\mathrm{cd}} \pm 2.06$ \\
\hline
\end{tabular}

Values are averages of triplicate determination with standard deviations. Means in the same column with the same letters aren't significantly different (Duncan; $\mathrm{p} \leq 0.05$ ), samples description—as Table 1

Table 4 Pearson correlation matrix between rheological parameters of the milk dessert

\begin{tabular}{|c|c|c|c|c|c|c|c|c|}
\hline Variables & $\mathrm{H}$ & $\mathrm{S}$ & $\mathrm{C}$ & G & $\mathrm{Ch}$ & $\mathrm{A}_{\mathrm{T}}$ & $\mathrm{K}$ & $\mathrm{n}$ \\
\hline \multicolumn{9}{|c|}{ Milk desserts without $\kappa$-carrageenan } \\
\hline $\mathrm{H}$ & 1.00 & & & & & & & \\
\hline $\mathrm{S}$ & -0.30 & 1.00 & & & & & & \\
\hline $\mathrm{C}$ & 0.57 & 0.45 & 1.00 & & & & & \\
\hline G & $0.97 *$ & -0.36 & 0.62 & 1.00 & & & & \\
\hline $\mathrm{Ch}$ & $0.92 *$ & -0.02 & 0.84 & $0.94 *$ & 1.00 & & & \\
\hline $\mathrm{A}_{\mathrm{T}}$ & 0.46 & -0.75 & -0.46 & 0.37 & 0.08 & 1.00 & & \\
\hline K & $0.93 *$ & -0.40 & 0.27 & 0.84 & 0.72 & 0.73 & 1.00 & \\
\hline $\mathrm{n}$ & $-0.99 *$ & 0.34 & -0.47 & $-0.94 *$ & -0.86 & -0.57 & $-0.97 *$ & 1.00 \\
\hline \multicolumn{9}{|c|}{ Milk desserts with $0.1 \%$ k-carrageenan } \\
\hline $\mathrm{H}$ & 1.00 & & & & & & & \\
\hline$S$ & 0.03 & 1.00 & & & & & & \\
\hline $\mathrm{C}$ & 0.28 & $-0.94 *$ & 1.00 & & & & & \\
\hline G & $0.99 *$ & 0.14 & 0.16 & 1.00 & & & & \\
\hline $\mathrm{Ch}$ & $0.95^{*}$ & 0.21 & 0.07 & $0.99 *$ & 1.00 & & & \\
\hline $\mathrm{A}_{\mathrm{T}}$ & -0.51 & 0.33 & -0.57 & -0.36 & -0.23 & 1.00 & & \\
\hline $\mathrm{K}$ & 0.86 & 0.07 & 0.15 & $0.91 *$ & $0.95 *$ & -0.02 & 1.00 & \\
\hline $\mathrm{n}$ & -0.81 & 0.22 & -0.40 & -0.84 & -0.86 & 0.08 & $-0.96^{*}$ & 1.00 \\
\hline
\end{tabular}

Analysis of flow behavior showed the highest shear stress values for milk dessert with $0.1 \%$ oat gum concentration, an increase oat gum concentration above that level decreases shear stress, regardless of $\kappa$-carrageenan addition. The present study suggested that $\kappa$-carrageenan addition can significantly improve viscosity of milk dessert with oat gum, irrespectively to oat gum concentration. Moreover $\kappa$-carrageenan addition can stabilized the effect of oat gum concentration on hysteresis loop area; in this case increase in oat gum concentration slightly increase thixotropic area value. Combined addition of $0.1 \%$ oat gum 
and $0.1 \% \kappa$-carrageenan allows to obtain milk dessert with the highest hardness. Our result showed that $0.1 \% \mathrm{\kappa}$-carrageenan addition can improve rheological properties of milk dessert with oat gum concentration in the range from 0.1 to $0.5 \%$.

Open Access This article is distributed under the terms of the Creative Commons Attribution 4.0 International License (http://crea tivecommons.org/licenses/by/4.0/), which permits unrestricted use, distribution, and reproduction in any medium, provided you give appropriate credit to the original author(s) and the source, provide a link to the Creative Commons license, and indicate if changes were made.

\section{References}

Aguilar-Raymundo VG, Vélez-Ruiz JR (2018) Physicochemical and rheological properties of a dairy dessert, enriched with chickpea flour. Foods 7(2):25. https://doi.org/10.3390/foods7020025

Anttila H, Sontag-Strohm T, Salovaara H (2004) Viscosity of betaglucan in oat products. Agric Food Sci 13:80-87

Beer MU, Arrigoni E, Amando R (1996) Extraction of oat gum from oat bran: effect of process on yield, molecular weight distribution, viscosity and $(1 \rightarrow 3)(1 \rightarrow 4)-\beta$-D-glucan content of the gum. Cereal Chem 73(1):58-62

Bergfeldt K, Piculell L, Linse P (1996) Segregation and association in mixed polymer solutions from flory-huggins model calculations. J Phys Chem 100:680-3687

Gustaw W (2008a) Production and rheological properties of whey protein-polysaccharide mixed (composites) gels. Acta Aliment 37(3):359-365

Gustaw W (2008b) The effect of an oat- $\beta$-glucan addition on the physico-chemical properties of a set yoghurt. Milchwissenschaft 63(3):296-298

Gustaw W, Mleko S (1998) Functional properties and application of carrageenans in dairy technology (in Polish). Food Sci Technol Qual 1(14):71-80

Gustaw W, Szwajgier D (2012) Rheological properties of mixed gels of oat beta-glucan with whey proteins. Polimery 57(4):284-289

Gustaw W, Sołowiej B, Mleko S (2005) Making milk desserts of whey proteins with starch and carrgeenan added (in Polish). Food Sci Technol Qual 4(45):100-108

Keith M, Kuliszewski MA, Liao Ch, Peeva V, Ahmed M, Tran S, Sorokin K, Jenkins DJ, Errett L, Leong-Poi H (2014) A modified portfolio diet complements medical management to reduce cardiovascular risk factor in diabetic patients with coronary artery disease. Clin Nutr 34(3):541-548

Lazaridou A, Serafeimidou A, Biliaderis CG, Moschakis T, Tzanetakis N (2014) Structure development and acidification kinetics in fermented milk containing oat b-glucan, a yogurt culture and a probiotic strain. Food Hydrocoll 39:204-214

Mekhloufi G, Sanchez Ch, Renard D, Guillemin S, Hardy J (2005) $\mathrm{pH}$-induced structural transitions during complexation and coacervation of $\beta$-lactoglobulin and acacia gum. Langmuir 21:386-394

Mleko S, Gustaw W (2002) Rheological changes due to substitution of total milk proteins by whey proteins in dairy desserts. J Food Sci Technol 39(2):170-172

Mleko S, Li-Chen E, Pikus S (1997) Interactions of $\kappa$-carageenan with whey proteins in gels formed at different $\mathrm{pH}$. Food Res Int 30(6):427-433
Nastaj M, Gustaw W, Sołowiej B (2007) The rheological properties of milk desserts obtained from the whey proteins with the addition of different sweeteners (in Polish). Food Sci Technol Qual 5(54):283-291

Nishinari K, Kohyama K, Kumagai H, Funami T, Borune MC (2013) Parameters of texture profile analysis. Food Sci Technol Res 19(3):519-521

Patel S (2015) Cereal bran fortified-functional foods for obesity and diabetes management: triumphs, hurdles and possibilities. J Funct Food 14:255-269

Qasem AAA, Alamri MS, Mohamed AA, Hussain S, Mahnood K, Braheem MA (2017) High soluble-fiber pudding: formulation, processing, texture and sensory properties. J Food Process Preserv 41(3):12931. https://doi.org/10.1111/jfpp.12931

Queenan KM, Stewart ML, Smith KN, Thomas W, Fulcher RG, Slavin JL (2007) Concentrated oat $\beta$-glucan, a fermentable fiber, lowers serum cholesterol in hypercholesterolemic adults in a randomized controlled trial. Nutr J 6:6

Reis FR, de Pereira-Netto AB, Meira SJL, Isidoro HCW, Bilesky CLM (2011) Apparent viscosity of a skim milk based dessert: optimization through response surface methodology. Food Nutr Sci 2:90-95

Reppas C, Swidan SZ, Tobey SW, Turowski M, Drressman JB (2009) Hydroxymethylcellulose significantly lowers blood cholesterol in mildly hypercholesterolemic human subjects. Eur J Clin Nutr 63:71-77

Sayar S, Jannink L, White PJ (2006) In vitro bile acid binding activity within flour fractions from oat lines with typical and high $\beta$ glucan amount. J Agric Food Chem 54:5142-5148

Sivaramakrishnan HP, Senge B, Chattopadhyay PK (2004) Rheological properties of rice dough for making rice bread. J Food Eng 62:37-45

Szwajgier D, Gustaw W (2015) The addition of malt to milk-based desserts: influence on rheological properties and phenolic acid content. LWT Food Sci Technol 62:400-407

Tárrega A, Costell E (2006) Effect of inulin addition on rheological and sensory properties of fat-free starch-based dairy desserts. Int Dairy J 16:1104-1112

Tárrega A, Duran L, Costell E (2004) Flow behaviour of semi-solid dairy desserts. Effect of temperature. Int Dairy J 14:345-353

Toker OS, Dogan M, Caniyilmaz E, Ersöz NB, Kaya Y (2013) The effects of different gums and their interactions on the rheological properties of a dairy dessert: a mixture design approach. Food Bioprocess Technol 6:896-908

Turgeon SL, Beaulieu M (2001) Improvement and modification of whey protein gels texture using polysaccharides. Food Hydrocoll 15:583-591

Weickert M, Mohlig M, Schofl C, Arafat A, Otto B, Viehoff H, Koebnick C, Kohl A, Spranger J, Pfeiffer A (2006) Cereal fiber improves whole-body insulin sensitivity in overweight and obese women. Diabetes Care 29:775-780

Wolever TMS, Tosh SM, Gibbs AL, Brand-Miller J, Duncan AM, Hart V, Lamarche B, Thomson BA, Duss R, Wood PJ (2010) Physicochemical properties of oat $\beta$-glucan influence its ability to reduce serum LDL cholesterol in humans: a randomized clinical trial. Am J Clin Nutr 92:723-732

Wood P, Braaten JT, Scott FW, Ridel KD (1994) Effect of dose and modification of viscous properties of oat gum on plasma glucose and insulin following an oral glucose load. Br J Nutr 72:731-743

Publisher's Note Springer Nature remains neutral with regard to jurisdictional claims in published maps and institutional affiliations. 